\title{
The Construction of College English Online Learning Community under ADDIE Model
}

\author{
Jianfeng Zhang ${ }^{1}$ \\ ${ }^{1}$ College of Humanities and Foreign Languages, Xi' an University of Science and Technology, China \\ Correspondence: Jianfeng Zhang, College of Humanities and Foreign Languages, Xi'an University of Science \\ and Technology, Lintong District, Xi'an, Shaanxi Province, 710600 China.
}

Received: May 13, 2020

doi: $10.5539 /$ elt.v13n7p46
Accepted: June 8, 2020

Online Published: June 9, 2020

\begin{abstract}
Based on collaborative communication, reciprocal learning, and knowledge sharing, the college English online learning community, which is a kind of effective online learning method, can help to build knowledge construction and innovation. Therefore, from analysis, design, development, implementation and evaluation, ADDIE model is utilized to construct college online learning community that is fully combined with network environment, learners, teachers and learning resources, so that English learners' integrative competences and the level of knowledge construction can be developed; meanwhile, the performance of college English online teaching will be promoted.
\end{abstract}

Keywords: ADDIE, college English, online learning, learning community

\section{Introduction}

The importance of online teaching and learning has been highlighted in early 2020 because of the COVID-19 pandemic. Some problems, however, have been reflected in the learning practices. For example, there exists strong aloneness while online learning; learners are less collaborative and lower motivation; the process of learning lacks incentive mechanism. Therefore, based on ADDIE model, college English online learning community, which can form efficient learning group, will be constructed and learners are able to actively participate in the whole process of online learning via developing collaborative inquiry learning so that the performance of English teaching and learning will be promoted effectively.

\section{Literature Review}

\subsection{ADDIE Model}

ADDIE is a flexible instructional model that is developed and designed by Centre for Educational Technology, Florida State University, including 5 phases called Analysis, Design, Development, Implementation, and Evaluation (Maddison \& Kumaran, 2017). These five phases, which are interconnected and interacted with each other, are nonlinear cyclic modes.

Based on learners' learning need analysis and teachers' capacity analysis, the first phase is analysis, which will analyze teaching objectives, teaching content and teaching environment. It is the premise of carrying out teaching practice; on the basis of analysis, design means to arrange learning resources and to design learning strategies according to teaching objectives, which is the foundation to launch teaching practice smoothly; once the design phase is completed, the next phase is development, which will sort out teaching materials and generate related curricula; in the implementation phase, classroom teaching is conducted and knowledge is transferred; evaluation will monitor and test the whole process of teaching and learning. Finally, an assessment report that determines the success of learning outcomes will form. (Ngussa, 2014)

These five phases are interrelated and mutually promoted: analysis and design are the premise and basis of teaching; development and implementation are the core of teaching; evaluation is the strong guarantee of the whole teaching mode. Every phase, moreover, can enter the evaluation phase at any time. According to the feedback, the next phase will be decided whether or not to move on so that the whole teaching process can be finished successfully. All five phases are summarized in the following Figure 1.

Morrison (2010) points out that in curriculum design ADDIE is a set of scientific development model for 
teaching \& learning systems and is a common curriculum implementation plan. Therefore, based on ADDIE model, the college English online learning community will be constructed to improve the effective interaction between learners and teachers, learners and learners, teachers and teachers so that the performance of English online teaching can be promoted efficiently.

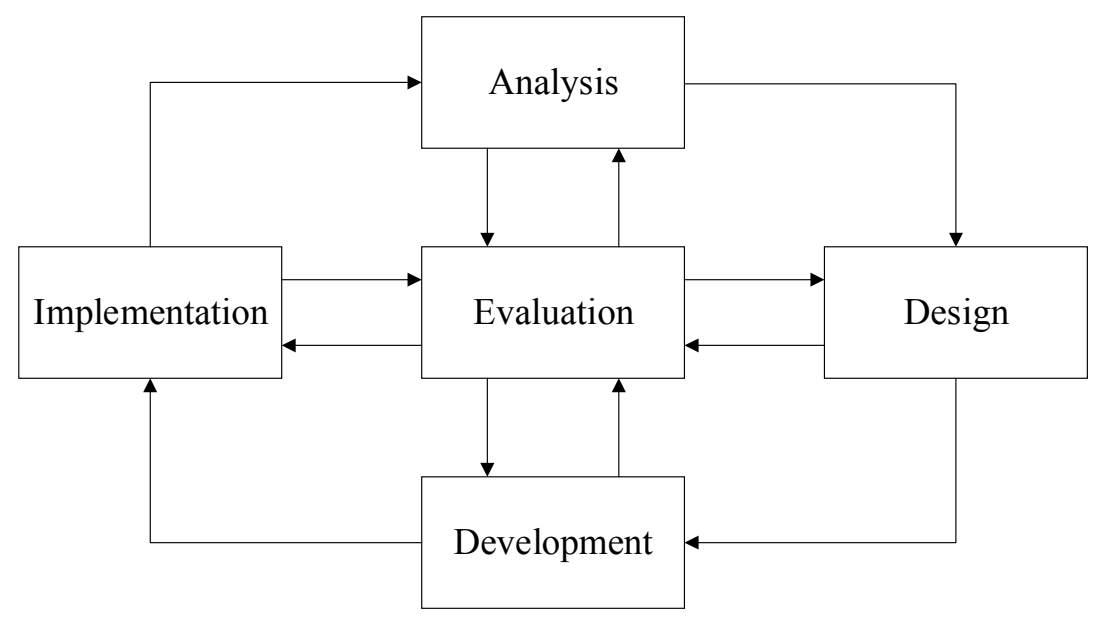

Figure 1. ADDIE Model (adapted and modified Morrison, 2010)

\subsection{Online Learning Community}

The concept of learning community originated from the 1960s, and it has become popular in American higher education in the late 1990s. Lave and Wenger (1991) proposed the community of practice that is regarded as an important foundation for the theory of learning community. They believe that knowledge, community and practice are the three elements for community of practice. Knowledge determines the interests and identities of community members; community determines learning situation; and practice can determine the practical application of knowledge and the acquisition of new knowledge. Therefore, community of practice can develop and enhance the effective learning. Richard (2004) put forward the concept of professional learning community. He proposed that profession learning community should focus on learning rather than teaching; learning outcome should be scientifically analyzed, and autonomous learning, collaborative learning and learning outcome are the three cores of profession learning community.

Learning community, therefore, refers to the way of learning and teaching organization formed by learners, teachers and teaching administrators. Knowledge construction and innovation can be achieved via collaborative communication, reciprocal learning and knowledge sharing. (Li \& Wang, 2018)

With the development of information technology and due to the public health emergencies, all kinds of schools have great demands for online teaching; meanwhile, online learning has become the preferred way for learners. So, using the network platform, a group, which learners and teachers communicate, exchange ideas and get together for the same curriculum learning, is called online learning community.

There are three characteristics of college English online learning community: (a) Members have the same learning willingness. The learning objective of all members is college English curriculum and the strong feeling of dependency and belonging exists among the members, so the centripetal force and cohesion can be easily formed. The same learning willingness is the foundation on which online learning community can exist. (b) There are differences among learners. Although learners gather on the Internet platform for the purpose of English learning, the long-term stability of learning community can be affected due to the differences of individuals and knowledge reserve. It is a problem to be solved in construction of online learning community. (c) The whole system has openness. Knowledge is presented in the form of shared resources on the network platform without the limitation of time and space; therefore, the organizational system of online learning community should have corresponding openness to meet the different learners' needs and to support the improvement of members' abilities.

\section{The Construction of College English Online Learning Community}

College English online learning community is a learning group that takes learners and teachers as the core factor and utilizes network equipment to communicate each other, share resources, assist and influence each other to finish specific English learning tasks. Based on the ADDIE model, in the process of the construction of college English online learning community, the five phases of analysis, design, development, implementation and 
evaluation should be fully grasped to perfectly merge some factors such as learning environment, learners, teachers, learning resources so that learners' comprehensive skills and knowledge construction level can be significantly improved and college English teaching performance can be promoted as well.

\subsection{Analysis}

Analysis is the first step in the construction of college English online learning community. Teachers need to make comprehensive analysis of learners and themselves to learn about what learners need and what they can provide. Therefore, in the analysis phase, the research should be carried out from two aspects: one is learners' need analysis; the other is teachers' capacity analysis.

\subsubsection{Learners' Need Analysis}

According to theory of Hutchinson \& Waters (1987), learners' needs can be divided into target needs and learning needs. The former is the necessities, lacks and wants in the context of language learning objectives; the latter is learners' learning background, learning attitude, learning content and learning environment. In the construction of college English online learning community, the actual situation should be clearly defined and learners' needs should be fully analyzed, which are the basis for making joint learning plans, selecting learning materials, and developing collaborative learning.

Teachers can make effective statistics on English learners' knowledge background, learning willingness, learning content, learning objectives, online learning environment and methods through questionnaires and interviews. Teachers should fully understand what language skills need, what key knowledge lacks, and what integrated abilities must be mastered; meanwhile, teachers should carefully analyze online learners' learning and personality characteristics so that English learners can thoroughly exert their subjective initiative in the learning community and actively participate in the process autonomous inquiry learning and collaborative learning.

\subsubsection{Teachers' Capacity Analysis}

The construction of college English online learning community is a systematic project, which requires the close cooperation between learners and teachers. In addition to the excellent professional knowledge, teachers must constantly improve their own capacities and the structure of quality so as to meet the needs of online teaching. Teachers' capacity analysis can help them to form the dominant concept of integration of technology and teaching, to deepen the understanding of learners' thinking, cognitive and learning in the network environment. (Zhang \& Liu, 2105)

Firstly, language teachers should have information processing capacity, which is the basic ability to construct online learning community. With the application of network technology, teachers are able to skillfully obtain information and to deliver or communicate information to members of learning community through processing and transformation, so as to guarantee the sustainability of online learning. Then, language teachers should have the capacity of online teaching design. According to characteristics of online learning, teachers can systematically design and comprehensively consider the college English teaching content, time, process and other important elements, so as to closely combine the theoretical teaching with authentic language application and to promote the development of learners' comprehensive practical skills in English. Thirdly, language teachers should have the capacity to integrate information. Online learning breaks the limitation of time and space and leaning materials emerge in an endless stream. Teachers should not only be good at obtaining materials and improving the utilization rate of material, but also be able to integrate various materials for learners to better serve online teaching and to improve the members' learning efficiency. Finally, language teachers should have the capacity of learning monitor. On the one hand, teachers should grasp and control the whole process of online learning and communication, and supplement or adjust English learning strategies according to the actual situation to achieve the best learning outcome; on the other hand, teachers should timely reflect on their own teaching behavior, constantly revise, adjust or improve the teaching process through the feedback of the learning community, and successfully form their own online teaching style and characteristics.

\subsection{Design}

After the learners' need analysis and teachers' capacity analysis, the learning process of online learning community needs to be designed carefully. In this phase, the characteristics of English learning should be highlighted; moreover, learning objectives, learning strategies, learning modules and learning activities should be designed reasonably so that the needs of online learning community can be met.

\subsubsection{The Design of Learning Objectives}

The learning objectives of college English learning community are to reserve enough language knowledge via 
online learning and to proficiently use English to communicate in the authentic context. Therefore, in the design of learning objectives, it is necessary to cultivate the comprehensive skills of English and to make learners clear the orientation of English learning. Language teachers and learners should fully communicate and cooperate with each other to assist learners in the establishing correct concept of English learning, so as to enhance learning initiative and to stimulate learning motivation.

\subsubsection{The Design of Leaching Strategies}

Although online learning breaks the limitation of teaching space, simply watching videos and practicing online will lead to increased loneliness and influence the English learning effects. So, in the design of learning strategies, it is necessary to make use of the open characteristics of Internet and to adopt some learning strategies, such as task-driven, group discussion, presentation, etc. to improve the learners' sense of engagement and recognition of learning objectives; simultaneously, language knowledge can be transferred effectively.

\subsubsection{The Design of Learning Modules}

Combined with learning objectives and learning strategies, the learning modules are designed to mark language points and to arrange learning environment. For teachers, the modules of curriculum management and evaluating service are designed to manage the whole learning process uniformly, to improve the uploading, reviewing and sharing mechanism of learning resources and to store teaching materials such as electronic textbooks, courseware, teaching plans and so on. Moreover, by the module of evaluating service, teachers can monitor the learning, keep track of learners' learning progress and adjust the learning strategies according to the actual situation.

For learners, modules of forum discussion are designed to conduct online language drills and practices. Based on the learning themes, learners communicate in the way of speech, texts or pictures. So, in the process of online language learning, there are teachers' explanation \& monitor, and learners' discussional language output. Members of online learning community can carry out inquiring and collaborative learning in the authentic context to mutual fluency and promote so as to the learning tasks that can be completely successful.

\subsubsection{The Design of Learning Activities}

Learning activities of online learning community mainly focus on the themes of English learning. Usually teachers should set learning topics and environments according to the syllabus. When designing learning activities, teachers need to assign some tasks with certain complexity and authenticity to stimulate learning motivation, which can guide learners to make English to illustrate, communicate and discuss flexibly and can encourage learners to participate online learning community actively so that self-efficacy can be enhanced and the language knowledge can be constructed.

\subsection{Development}

Based on analysis and design, in the development phase, online learning community should meet the actual needs of college English learning, and the main work is to develop learning tasks, to prepare for the learning materials and produce relevant leaning video and audio.

\subsubsection{The Development of Learning Tasks}

According to the learning objectives and needs, teachers make use of pictures, video or audio to develop learning tasks. On one hand, the key points, difficulties and plans of language learning are integrated into the tasks; at the same time, sufficient language knowledge, which can help fully activate the background knowledge, is provided to learners to prepare for the implementation of learning tasks. On the other hand, teachers should utilize information technology to develop more complex learning tasks so as to ensure that learners can successfully complete all tasks applying various language skills such as learning, speaking, reading, writing and translating, which will fully improve their English comprehensive applied abilities.

\subsubsection{The Development of Learning Materials}

According to learning tasks, teachers should prepare for the corresponding texts, video or audio of learning materials so that learners can learn about learning content in advance. (Park, 2009) Meanwhiles, learners, as the main members of learning community, can actively consult, sort out, summarize, upload and share useful learning materials in advance according to learning tasks and can make preparation for the post inquiring and collaborative learning.

\subsubsection{The Development of Learning Video and Audio}

Pure online learning by using multimedia resources such as video and audio can play a positive role in 
promoting college English. (Han, 2010) However, it should be noted that both the materials from the Internet and the video or audio edited or recorder by teachers should be targeted and the key language points should be fully explained but the time should not be too long; otherwise, the learners' cognitive load will be burdened and the learning performance will be seriously influenced. On the other hand, teachers should strictly check these video and audio materials uploaded or shared by learners and should eliminate those that are inappropriate and too difficult to ensure the high quality of multimedia learning resources.

\subsection{Implementation}

Only after the adequate analysis, design and development, the learning tasks of learning community can be implemented smoothly so as to ensure knowledge construction and to promote deep learning. First of all, teachers should be the organizers and monitors of the members of learning community. Through the preliminary preparation, learning tasks can be decomposed reasonably according to the degree of complexity and can be assigned to learners. Meanwhile, it is necessary to avoid the chaotic state of learners when they are in autonomous learning, to organize discussions and answer questions timely so that learning quality can be guaranteed and learning efficiency can be enhanced. What's more, language learners have to be the subjects of learning community. They should actively participate in the learning activities and carefully complete the learning tasks by means of inquiring and collaborative learning; they can construct the learning community through online discussions, role playing and other forms so that they can apply language knowledge to solve practical problems and to engage in deeper-level communication; besides they should adjust their learning strategies and habits in time according to the feedback from teachers and peers so that English learning can focus on cultivating comprehensive skills rather than staying in the low-level stage of memorizing words and grammar. (Chen et. al, 2017)

\subsection{Evaluation}

The evaluation phase, which diagnoses and assesses at each phase of analysis, design, develop and implementation, should be appeared throughout the whole process of the construction of college English online learning community; according to the evaluation results, every phase can be adjusted timely, so language learning activities can be completed successfully and smoothly. On one hand, teachers communicate with learners through Internet platforms and gain opinions and suggestions on analysis, design and development; moreover, teachers learn about learners' views and feeling on learning tasks and activities via questionnaires, interviews and other ways. According to the positive or negative feedback, the construction of learning community can be adjusted, improved and promoted in time. On the other hand, at the end of implementation, learners carry our self-evaluation and peer evaluation through the demonstration of learning results. In the process of evaluation, it is necessary to pay much attention to the discovery and solution of problems. Evaluation results can judge whether members of learning community participate in learning activities actively, whether language knowledge can be internalized successfully, and whether English comprehensive skills have been enhanced so as to provide enough reference and basis for a new round of learning.

\section{Conclusion}

Online teaching and learning are inevitable trends in the age of educational informationalization and college English online learning community is the product that English teaching is deeply integrated with information technology. Based on ADDIE model, the construction of college English online learning community can accurately analyze, design, develop, implement and evaluate learning activities to help members of learning community better communicate and cooperate in the process of language learning so that learners can internalize, apply and innovate knowledge to effectively promoter their English comprehensive abilities.

\section{References}

Chen Wenjuan, Wang Na, \& Li Jinyu (2017). The Construction of Learning Community Based on SPOC Forum: A Case Study of College English Teaching in SPOC Flipped Classroom. Journal of Xi'an International Studies University, 25(4), 58-61.

Han Yanhui. (2010). The Instructional Design of Multimedia Interactive English Learning Resources Based on ADDIE Model: A Case Study of Pure Online Informal Learning Environment. Modern Distance Education, 127(1), 72-76.

Hutchinson, T., \& Waters, A. (1987). English for Specific Purposes. Cambridge University Press, Cambridge. https://doi.org/10.1017/CBO9780511733031

Lave J., \& Wenger E. (1991). Situated Learning: Legitimate Peripheral Participation. Cambridge University Press. https://doi.org/10.1017/CBO9780511815355.006 
Li Haifeng, \& Wang Wei. (2018). Construction of Learning Community Online based on Social System Theory. China Educational Technology, 6, 77-85.

Maddison T., \& Kumaran M. (2017). Distributed Learning: Pedagogy and Technology in Online Information Literacy Instruction. Chandos Publishing. https://doi.org/10.1016/C2015-0-00018-1

Morrison, G. R. (2010). Designing Effective Instruction (6th Edition.). John Wiley \& Sons. https://doi.org/10.4135/9781452232379.n4

Ngussa, B. M. (2014). Application of ADDIE Model of Instruction in Teaching-Learning Transaction among Teachers of Mara Conference Adventist Secondary Schools, Tanzania. Journal of Education and Practice, 5(25), 1-11. https://doi.org/10.12691/education-2-11A-1

Park, S. Y. (2009). An Analysis of the Technology Acceptance Model in Understanding University Students' Behavioral Intention to Use e-Learning. Educational Technology \& Society, 12(3), 150-162. https://doi.org/10.1109/IIAI-AAI.2014.14

Richard DuFour. (2004). What Is a Professional Learning Community? Educational Leadership, 61(8), 6-11. https://doi.org/10.1007/978-1-4020-9417-0_9

Zhang Jing, \& Liu Ganhong. (2015). Development Mechanism and Cultivation Path of Teachers' TPACK from Multi-Dimensional Perspectives. Journal of Distance Education, 33(3), 95-102.

\section{Copyrights}

Copyright for this article is retained by the author(s), with first publication rights granted to the journal.

This is an open-access article distributed under the terms and conditions of the Creative Commons Attribution license (http://creativecommons.org/licenses/by/4.0/). 